\title{
Modeling the Effects of Steel Catenary Riser (SCR) Wall Thickness on Its Structural and Fatigue Performances for Wave-Induced Load
}

\author{
Moses. E. Dapa \\ Offshore Technology Institute (OTI), Faculty of Engineering, University Of Port Harcourt, Nigeria. \\ Tobinson A. Briggs* \\ Mechanical Engineering, University of Port Harcourt, Choba, Port Harcourt, Nigeria \\ John U. Okoli (Professor) \\ Mechanical Engineering, Faculty of Engineering, University Of Port Harcourt, Nigeria
}

\begin{abstract}
The Steel Catenary Riser (SCR) exhibits significant bending and oscillation owing to undue vessel (which the riser is attached to) movements. The prevalent hydrodynamic loads (wave, current, hydrostatic pressure) are the leading causes of this structural behavior. These initiate a motion - related fatigue phenomenon. This study evaluates the feasibility of increasing the SCR Wall Thickness (WT) for better fatigue performance and structural responses when subjected to the dominant wave spectrum (Ochi Hubble) in deep water West Africa. Relevant data were acquired from an offshore facility in the study area and managed empirically through the use of marine structural analysis software- ORCAFLEX ${ }^{\circledR}$. Following Det Norske Veritas (DNV, 2010) methodology, 4 SCRs of uniform Internal Diameters (ID) were designated (SCR1, SCR2, SCR3, SCR4), modeled with different WTs (0.0626ft, 0.1876ft, $0.3126 f t, 0.4376 f t$ ) and analyzed under eight wave load cases. Before the fatigue assessments, the systems were analyzed for static and dynamic responses. Results showed that increasing the WT increases the Fatigue Life (FL) only along each riser arc length - from top to bottom. It was also observed from the systems' structural response analyses that the effective tension at the Hang off Point (HOP) increases with increase in WT and a compromise in the capacity of the SCRs to flex alongside the hydrodynamic loads due to cumulative rise in the weight of the system. This eventually lowered the FL at the HOP below the DNV's minimum FL for design purposes -200 years.
\end{abstract}

Keywords: Steel Catenary Riser, Wall thickness, Fatigue Performance, Ochi-Hubble, Structural response.

DOI: $10.7176 / \mathrm{ISDE} / 10-6-03$

Publication date:July $31^{\text {st }} 2019$

\subsection{Introduction}

The deepwater operation has increased with the development of technologies that have enabled efficient oil recovery in this terrain (Ruswandi, M. I.,2009). However, exploration in deep waters poses several environmental challenges, such as:
i. $\quad$ Increased hydrostatic pressure as a result of increased water depth (WD).
ii. Prevalent meteorological and hydrodynamic behavior due to the wind, current, and wave loads.
iii. $\quad$ Low seabed temperature which creates concern in terms of fluid flow.
iv. Marine growth effect, which adds to the weight of the riser system (Ruswandi, M. I.,2009).

Before the early 1990s, the flexible riser - a precursor to the SCR has been one of the dominant riser concepts for deep-water operations. Its installation simplicity and capacity to manage high bending stresses at mid-WD made it stand out. As oil recovery operations advanced into greater depths and harsher environment, the tendency of the flexible riser to withstand the prevailing hydrodynamic condition as a sole RS becomes questionable. As such, improved technological developments for the riser system (RS) are being adapted to effectively and economically deliver the produced fluid from subsea facilities (Campbell, M., 1999). The Steel Catenary Riser (SCR) is one of such systems usually preferred due to its better rating in terms of design and construction processes, suitability to host platform and its cost aspects, thus almost overthrowing the conventional flexible risers (Buberg, T., 2014).

However, this cost-effective technology innovation is highly vulnerable to fatigue failure arising from the impact of the Hydrodynamic Loads (HL) and an indirect impact that was attributed to vessel motion on which the riser was attached to (Ruswandi, M. I.,2009). The impact of these differs lengthwise in the SCR - from top to down. The three major sections of the SCR that are prone to this fatigue effect are the Touch Down Zone(TDZ) due to soil-riser interaction, the Hang Off Point (HOP) owing to high tension effects and the welded joints (hot spots) majorly because of stress concentration. On account of these, the Fatigue Life (FL) of the SCR becomes a significant consideration in its design philosophy (DNV-RP-F204; 2010). 
DNV, 2010 recommends that the designs for fatigue were evaluated on the contributory factors of the fatigue which include;
i. Wave motion effects on the vessel.
ii. $\quad$ Pressure components.
iii. Temperature effects.
iv. $\quad$ Vortex-Induced Vibration (VIV).

Technically, the SCR has been improved in terms of its configuration and functionality in a bid to ensure better performance as it plunges into deeper and rugged waters. A few of such innovations include the Lazy Wave, Lazy S-Shape SCR, and the weight distributed SCR (Karunakaran, D., Kristoffersen, S., \& Subsea 7., 2005).

\section{STEEL CATENARY RISER SYSTEM}

The SCR is a riser concept composed of steel material that is typically connected vertically to an offshore floater structure (semi-submersible, FPSO, TLP) via flexible joint (at the HOP) and anchored horizontally to the riser base at the seabed (the TDZ) while it basically assumes a catenary shape (Bridge, I., \& Howells, H., 2007) as shown in Fig. 1.

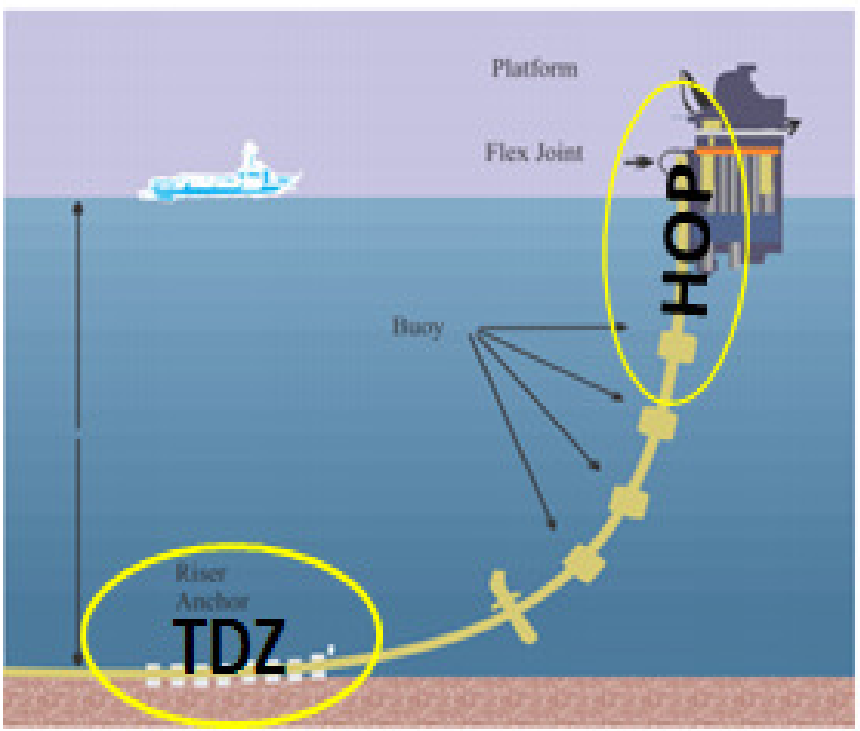

Figure 1: Pictorial Model of an SCR attached to an FPSO.

And the respective $\mathrm{X}$ and $\mathrm{Y}$ coordinates of a typical SCR can be represented by Equations 1 and 2 (Nelson, A. L., Folley, K. W., \& Coral, M. (1952).

$$
\begin{aligned}
& X=C * \cosh ^{-1}\left(\frac{Y}{C}+1\right) \\
& Y=C *\left[\cosh \left(\frac{X}{C}-1\right)\right] .
\end{aligned}
$$

\subsection{Contemporary SCR Key Design Considerations}

Contemporary SCR designs put into consideration some critical parameters while also allowing for the unexplained variances that could exist within these parameters (Song, R. S., 2009). Typically, the design considerations are encapsulated in the following:

a) Load conditions: All of these are captured in Table 1.

b) Fatigue Performance: by (DNV-RP-F204; 2010, DNV-OS-F201., 2010) the riser design is in part based on the aftermath of likely failure modes. As a standard, the riser is designed with adequate FL to evade any potential fatigue-oriented failure. And they further reiterate that the fatigue assessment under the SN curve approach must satisfy the expression below:

$$
\mathrm{D}_{\mathrm{FOS}} \cdot \sum \mathrm{D}_{\mathrm{F}} \leq 1
$$

c) Size: the concept of sizing is one of the initial steps in the riser design concept since a collection of the sizing parameter forms a critical part in transforming the conceptual design to detailed design. According to (DNV-OS-F201., 2010), the nominal WT sizing follows Equation 3.

$$
t_{\text {norm }}=\frac{O D}{\frac{4}{\sqrt{3}} \cdot \frac{\min \left(F_{a} ; \frac{F_{D}}{1.15}\right)}{Y_{a} \cdot V_{s c}\left(P_{L 1}-P_{e}\right)}}+t_{c o r}
$$


Table 1: Load categorization for SCR designs (DNV-OS-F201., 2010).

\begin{tabular}{|c|c|c|}
\hline Environmental Loads & Functional Loads & $\begin{array}{l}\text { Pressure and Temperature } \\
\text { Loads }\end{array}$ \\
\hline $\begin{array}{c}\text { Hydrodynamic conditions } \\
\text { - Waves } \\
\text { - Current. } \\
\text { - Ice. }\end{array}$ & $\begin{array}{c}\text { Vessel motions } \\
\text { - Surge. } \\
\text { - Heave. }\end{array}$ & Thermal load. \\
\hline $\begin{array}{l}\text { Meteorological load: } \\
\text { - Wind effects. }\end{array}$ & $\begin{array}{l}\text { Payload from; } \\
\text { - } \quad \text { Construction tools. } \\
\text { - } \quad \text { Drilling equipment. }\end{array}$ & External hydrostatic pressure. \\
\hline $\begin{array}{c}\text { Geotechnical stresses } \\
\text { - Earthquake }\end{array}$ & $\begin{array}{l}\text { Weight of attached components } \\
\text { - Buoyancy } \\
\text { - Connectors. } \\
\text { - Marine growth. }\end{array}$ & $\begin{array}{c}\text { Internal fluid pressure. } \\
\text { - } \quad \text { Slug flow } \\
\text { - } \quad \text { Surging effect. }\end{array}$ \\
\hline
\end{tabular}

\section{DESIGN OF METHODOLOGY}

A summary of the systematic approach adopted for the research is shown in Figure 2 concerning (DNV-OS-F201., 2010), and the Legend also provided sideways.

\subsection{Riser design format.}

Four (4) distinct SCRs were defined (SCR1, SCR2, SCR3, SCR4), composed of Carbon Steel all of the 1.0416ft uniform Internal Diameter (ID) following Load to Resistance Factor Method (LRFM) as provided in (DNV-OSF201., 2010). The principle of the LRFD sees a structure to be adequate only if the load-to-resistance ratio is below the specified allowable factor for the structure. They are modeled with different WTs and attached to 4 respective FPSOs with the basic riser properties presented as Table 2.

Table 2: Properties of Riser Model.

\begin{tabular}{rlll}
\hline \multicolumn{1}{c}{ Variable } & Symbol & Value & Unit \\
\hline Inner Diameter & ID & 1.0416 & $\mathrm{ft}$ \\
Wall Thickness & WT & & \\
- SCR1 & & 0.0626 & $\mathrm{ft}$ \\
- SCR2 & & 0.1876 & $\mathrm{ft}$ \\
- SCR3 $\quad$ SCR4 & & 0.3126 & $\mathrm{ft}$ \\
Riser Length & $\mathrm{L}_{\mathrm{R}}$ & 0.4376 & $\mathrm{ft}$ \\
HOP Departure Angle & $\Theta$ & 5594 & $\mathrm{ft}$ \\
Riser Density & $\rho_{\mathrm{S}}$ & 10 & $\mathrm{Degrees}$ \\
Yield Stress & $\mathrm{SMYS}$ & 490.0590 & $\mathrm{lb} / \mathrm{ft} 3$ \\
Young's Modulus & $\mathrm{E}$ & 64.1060 & $\mathrm{KPsi}$ \\
Bending Stiffness & $\mathrm{EIXx}=\mathrm{EIYY}$ & $29.73 \mathrm{E} 3$ & $\mathrm{KPsi}$ \\
Axial stiffness & $\mathrm{EA}$ & $3.6141 \mathrm{E} 6$ & $\mathrm{lb} . \mathrm{ft} 2$ \\
Bending Radius & $\mathrm{MBR}$ & $393.41 \mathrm{E} 4$ & $\mathrm{lbf}$ \\
Poisson Ratio & $\mathrm{N}$ & 12.3031 & $\mathrm{ft}$ \\
Torsional Stiffness & $\varnothing$ & 0.290 & - \\
Design Life & $\mathrm{DL}$ & $2.5 \mathrm{E} 5$ & $\mathrm{lb} . \mathrm{ft} 2$ \\
\hline
\end{tabular}

Table 3 is a summary of the representative environmental properties where the various SCRs and their respective FPSO vessels were simulated and global analysis conducted using ORCAFLEX ${ }^{\circledR}$. 
Table 3: Environmental Properties of Representative Study Area.

\begin{tabular}{rll}
\hline Variable & Value & Unit \\
\hline Sea Properties & & \\
- Water Depth & 3937 & $\mathrm{ft}$ \\
- Seabed Profile & Flat & - \\
- Kinematic Viscosity & $14.53 \mathrm{E}-6$ & $\mathrm{ft} 2 / \mathrm{s}$ \\
- Sea Temperature & 50 & ${ }^{0} \mathrm{~F}$ \\
- Sea Water Density & 63.983 & $\mathrm{lb} / \mathrm{ft} 3$ \\
& 6365.88 & $\mathrm{lb} / \mathrm{ft} 3$ \\
Generic Wave Properties & & \\
- Direction & 180 & $\mathrm{Degrees}$ \\
- Height & 19.68 & $\mathrm{ft}$ \\
Period & 7 & $\mathrm{Second}$ \\
Current (Interpolated) & & $\mathrm{ft} / \mathrm{s}$ \\
- Speed & 2.297 & $\mathrm{Degrees}$ \\
- Direction & 180 & \\
\hline
\end{tabular}

\subsection{Design for fatigue limit}

The essential design criterion for this under the S-N curve method follows that of Equation 3 . The idea of $\mathrm{D}_{\mathrm{FOS}}$ is apposite in capturing the probability of fatigue failure. Conventionally, three different $\mathrm{D}_{\mathrm{FOS}}$ values $(3,6$, and 10) exist for riser concepts (by DNV standards) whose rankings are respectively 'low,' 'normal' and 'high.' These rankings are based on the safety class level and possible operating conditions of the riser system. Pertinently, the 'high level' safety class used for all 4 SCR models.

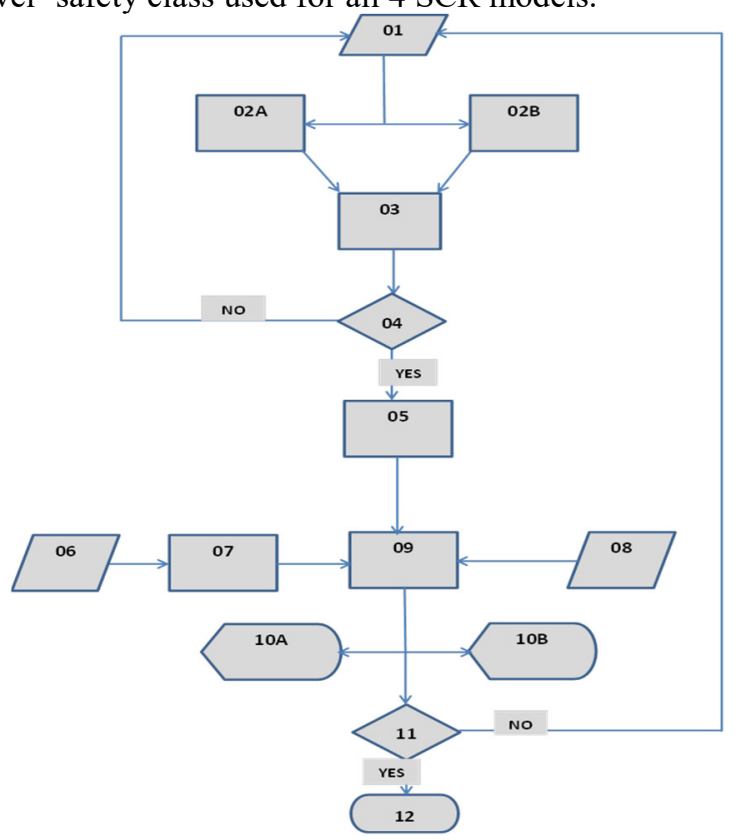

(Legend provided below).

01. Model Parameters:

- SCR and Vessel Properties.

- Environment properties.

- Seabed conditions

02A. SCR Model, 02B. Platform Model

03. Static Analysis.

04. Are the models in the equilibrium position?

05. Dynamic Analysis.

06. Collate Wave Scatter Data.

07. Generate Load cases depicting the study environment.

08. Read off SCF and S-N curve data from charts.

09. Perform Fatigue Analysis

10A. Record and extract fatigue life values and graphs,

10B. Record and extract fatigue damage values and graphs.

11. Is this the $4^{\text {th }}$ iterative SCR model fatigue analysis? 12. Finish.

Figure 2: SCR design and fatigue assessment methodology.

\subsection{Design for wave loads}

(DNVGL-RP., 2014, Chandrasekaran, S., 2018) affirm that the wave loads are the most prominent sources to fatigue loading. Generally, the principle of hydrodynamic force on marine structures is represented by Morrison's Equation, as shown in Equation 5 (which represents a variation of it for circular structures). Majorly, this equation finds application for structures whose diameter is relatively smaller than the besetting wavelength under consideration.

$$
F=\rho V C_{m} \ddot{U}+\frac{1}{2} \rho A C_{d} \dot{U}|\dot{U}|
$$

A practical way of capturing this dynamic phenomenon is by expressing it as a function of wave energy (spectrum). 
While different wave spectral exist with regards to the sea state of a geographical location, Ochi-Hubble- a six parameter wave spectrum were adopted for this study whose form is of Equation 6 as presented by (Ochi, M. K., \& Hubble, E. N., 1976). It is the most suitable wave spectrum that represents the properties of the waveform prevalent in the West of Africa. Its adequacy is justified as it allows for the use of 2-peaked spectra, which are locally-generated wind waves and remotely-generated swells. Table 4 provides the representative wave properties in the form of 'Load Cases' under which the fatigue analysis was carried out.

$$
\mathrm{S}_{\mathrm{o}}(\omega)=0.25 \sum_{\mathrm{j}=1}^{2} \frac{\left(\frac{4 \lambda_{\mathrm{j}}+1}{4} \cdot \omega_{\mathrm{pj}}^{4}\right.}{\Gamma\left(\lambda_{\mathrm{j}}\right)} * \frac{\mathrm{H}_{\mathrm{sj}}^{2}}{\omega^{4 \lambda_{\mathrm{j}}^{+1}}} * \exp \left[\left(-\frac{4 \lambda_{\mathrm{j}}+1}{4}\right)\left(\frac{\omega_{\mathrm{pj}}}{\omega}\right)^{4}\right]
$$

An ORCAFLEX ${ }^{\circledR}$ simulation extract (picture format) for one of the models is shown as Fig. 3.

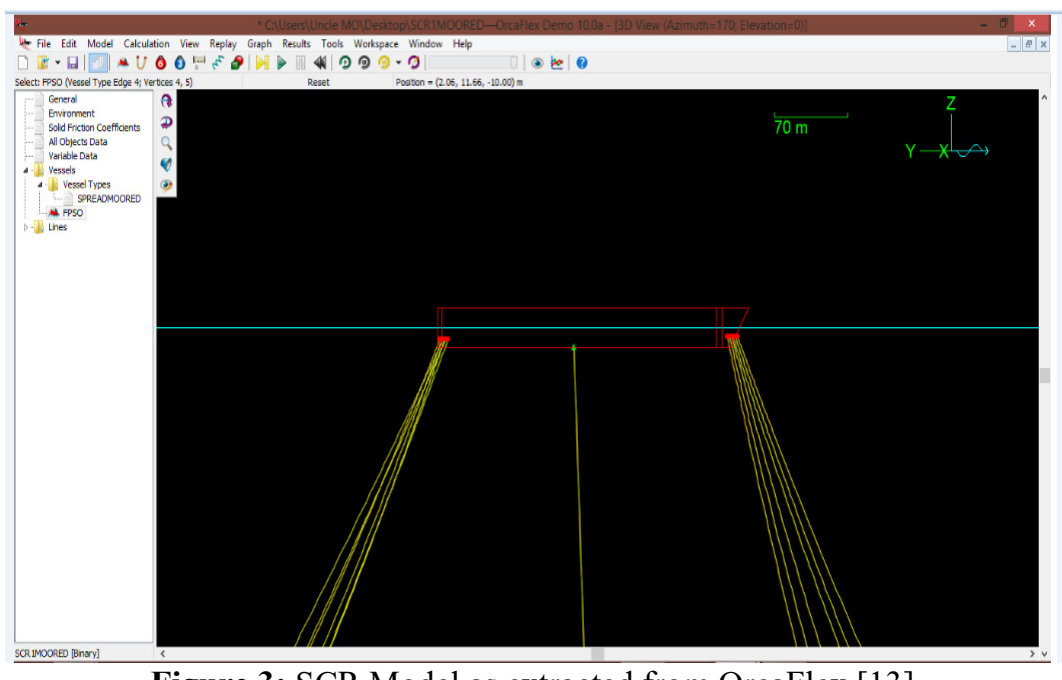

Figure 3: SCR Model as extracted from OrcaFlex [13].

\section{RESULTS AND DISCUSSIONS}

Figure 4 is the bending moment results (graphical) for all the SCRs under the static analysis. This Figure shows that the systems' response to bending forces decreases as the WT increased, with SCR4 (of highest WT) exhibiting the least bending behavior along its entire arc length. This observed trend was as a result of increased in the rigidity of the system by such an increase in thickness, hence costing the riser its 'curvature characteristic.'

The static analysis results also showed that the top tension component at the risers' HOPs increases with WT increase. A corresponding increase in the riser weight as its nominal thickness increased is a reason for this with Figure 5 showing this graphical relationship. Simulation results for the riser models in terms of their fatigue performances against the thickness variation have been put together as Fig. 6. It can be observed from the graph that the FL at the HOP drops as the riser thickness increased from $\mathbf{0 . 0 1 9 1 ~} \mathbf{m}$ (of SCR1) to $\mathbf{0 . 1 3 3 4} \mathbf{~ m}$ (of SCR4), with SCR4 having the lowest life value of 99 years while SCR1 (with the least WT value) had the highest fatigue life (699 years) at the HOP. However, each riser model tended to show an almost non-declining increase in FL from the top section to the TDZ. And this unique relationship was due to the decreasing effect of the representative wave load concerning WD increase. The FL of the SCRs for the worst damage scenario was also observed to be on the decline as the WT increased. These values, as calculated by ORCAFLEX ${ }^{\circledR}$, as shown in Figure. 7, and the worst damage FL value for SCR1 being 2089.67 years, followed by SCR2 with a life of 641.56 years. Whereas, SCR3 and SCR4 had their own worst damage fatigue lives to be 159.08 years and 102.25 years, which are relatively less than the minimum specified years for FL design by DNV's standards. 


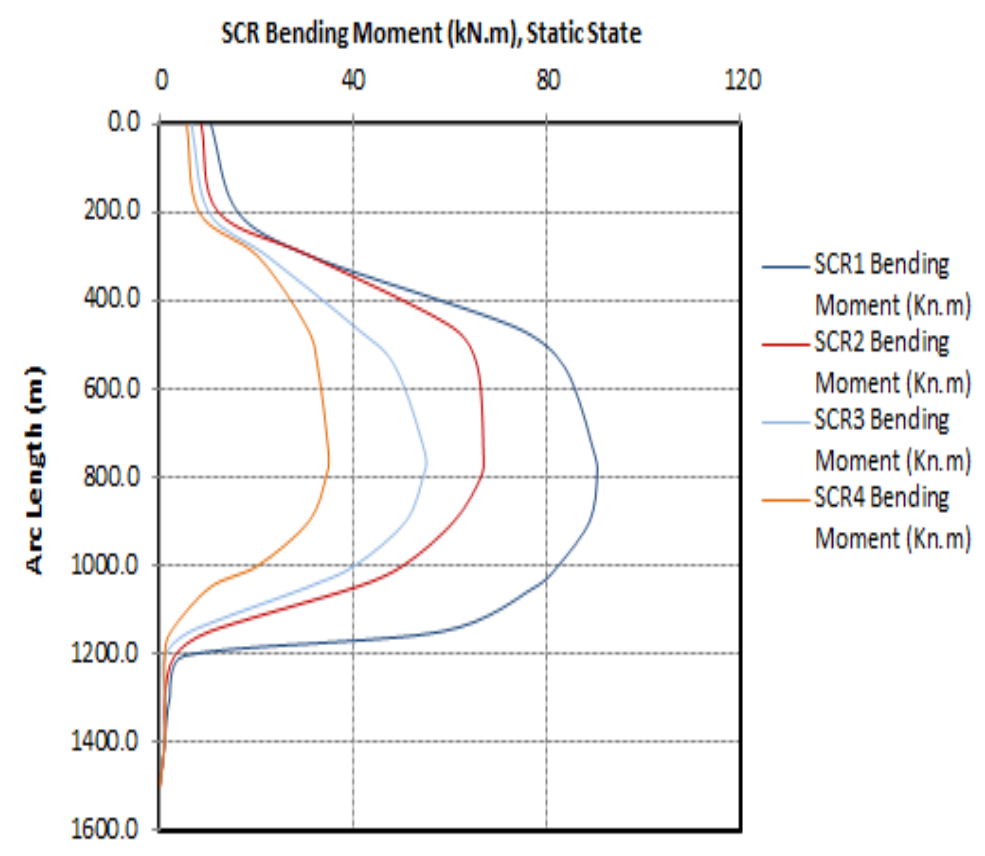

Figure 4: SCRs Bending Moment against Arc Length (Static State).

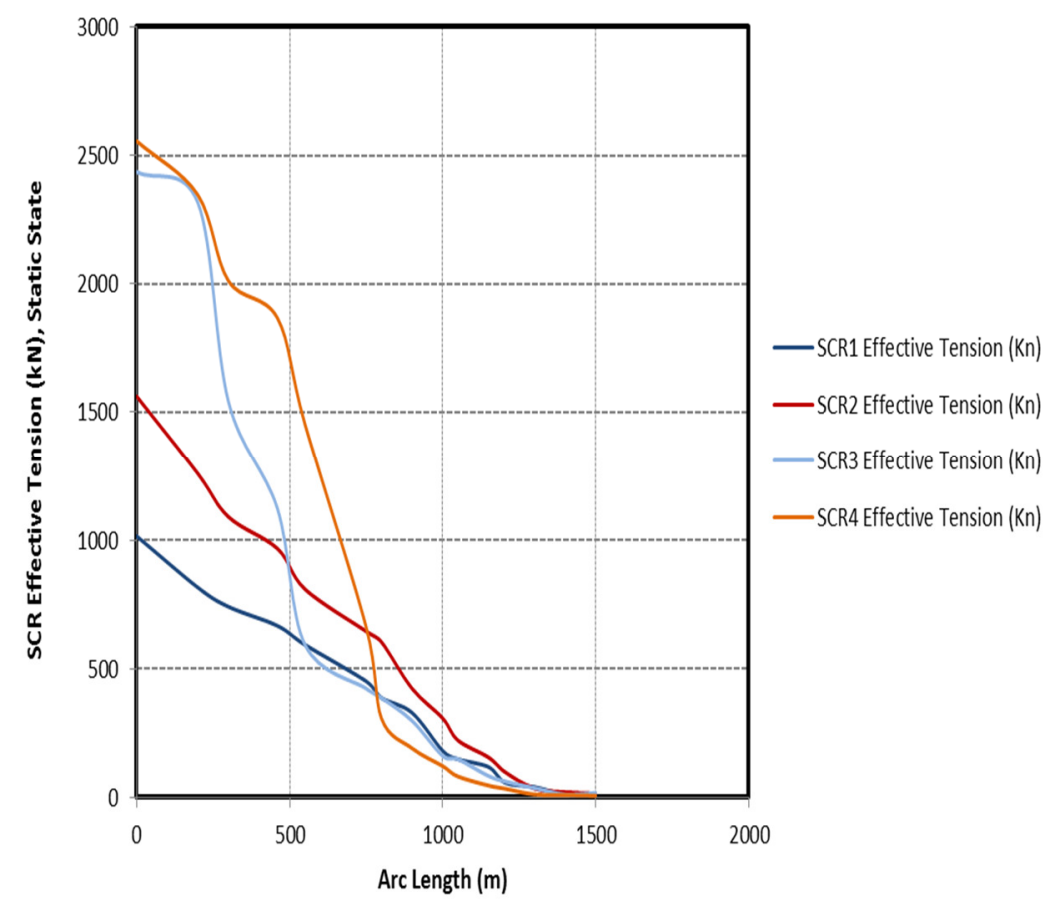

Figure 5: SCRs Effective Tension against Arc Length (Static State). 


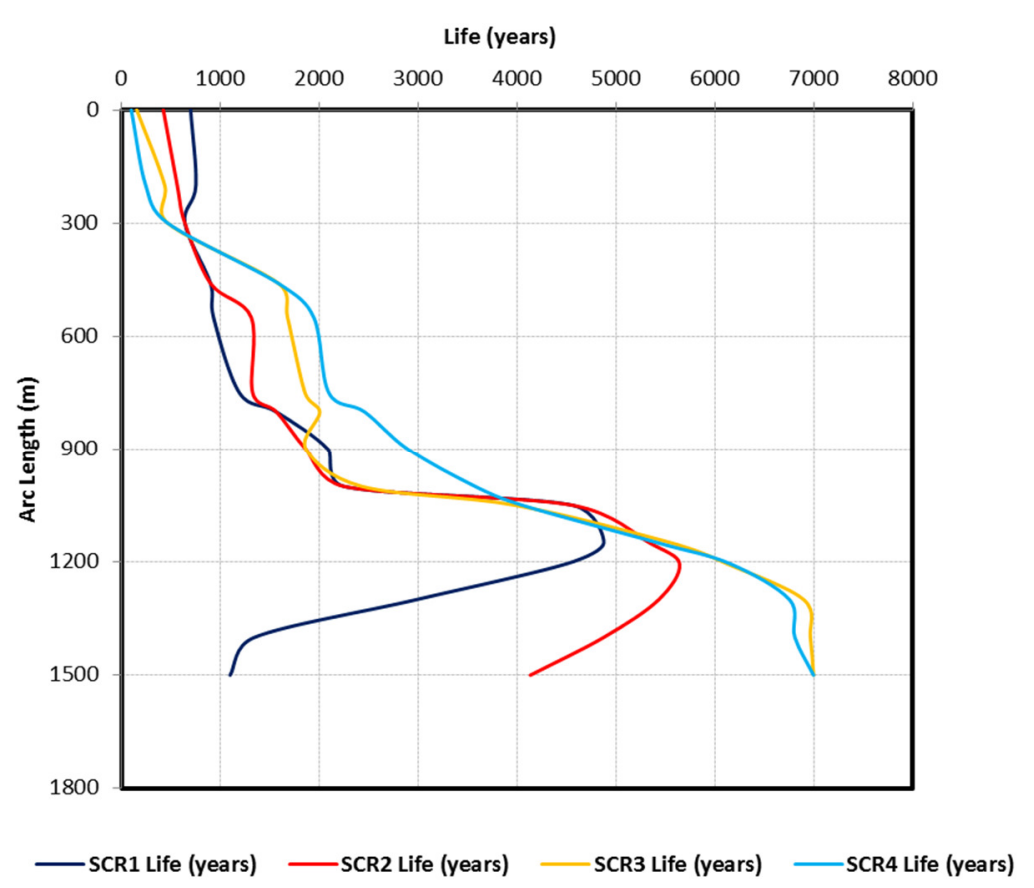

Figure 6: Fatigue Life trend along the arc length for all 4 SCRs.

\section{CONCLUSION}

The study focused on evaluating the effect of SCR Wall Thickness (WT) variation on its FL with an outlook to improve the system's performance against this pre-failure phenomenon for a West Africa deepwater operation. The performance modeling results for each of the SCR (as a single entity) under Ochi Hubble wave program showed that the WT variation (by increment) causes a rise in the fatigue life of the SCR from the HOP to the TDZ. Relatively, as the riser WT increased (from $\mathbf{0 . 0 6 2 6 f t}$ to $\mathbf{0 . 4 3 7 6 f t}$ ), its cumulative weight also increased, hence leading to a high top tension at the HOP. These, in turn, caused a significant drop in fatigue life at the HOP. Also, it was noticed from the worst damage simulation results that every increase in wall thickness brought the riser's fatigue life below the DNV's specified 200 years. Hence, making the increase of SCR wall thickness a technically ineffective choice for wave load-induced fatigue management as it does not satisfy DNV's standard. 


Fatigue Damage Summary
OrcaFlex 10.0d: SCR1.ftg (modified 15:28 on 12/10/2018 by OrcaFlex 10.0d)
Title:
Damage Calculation: Homogeneous pipe stress
Analysis Type: Rainflow
\begin{tabular}{|l|r|}
\hline \multicolumn{2}{|c|}{ Horst Damage } \\
\hline \multicolumn{2}{|c|}{$2.13655 \mathrm{E}-07$} \\
\hline Damage over Total Exposure & 0.0005 \\
Total Exposure Time (years) & 2089.6721 \\
Life (years) & 900.0 \\
Are Length (m) & 90.0 \\
Theta (deg) & S-N Curve1 \\
SN-curve & Outer \\
Radial Position & 1.27 \\
SCF & 0.25 \\
Thickness Correction Factor &
\end{tabular}

\section{Fatigue Damage Summary}

Droaflex 10.0d: SCR2.ftg (modified 16:27 on 12/10/2018 by OrcaFlex 10.0d) Title:

Damage Calculation: Homogeneous pipe stress

Analysis Type: Rainflow

\begin{tabular}{|l|r|}
\hline \multicolumn{2}{|c|}{ Horst Damage } \\
\hline Damage over Total Exposure & $7.85 E-04$ \\
Total Exposure Time (years) & 0.0005 \\
Life (years) & 641.56 \\
Arc Length (m) & 300.0 \\
Theta (deg) & 337.5 \\
SN-curve & S-N Curve1 \\
Radial Position & Outer \\
SCF & 1.27 \\
Thickness Correction Factor & 0.25 \\
\hline
\end{tabular}

\section{Fatigue Damage Summary}

DrcaFlex 10.0d: SCR3.ftg (modified 17: 15 on 12/10/2018 by DrcaFlex 10.0d) Title:

Damage Calculation: Homogeneous pipe stress

Analysis Type: Rainflow

\begin{tabular}{|l|r|}
\hline \multicolumn{2}{|c|}{ Horst Damage } \\
\hline Damage over Total Exposure & $3.23 \mathrm{E}-02$ \\
Total Exposure Time (years) & 0.0005 \\
Life (years) & 159.0851 \\
Arc Length (m) & 15.0 \\
Theta (deg) & \multicolumn{2}{|c|}{180.0} \\
SN-curve & S-N Curve1 \\
Radial Position & Outer \\
SCF & \multicolumn{2}{|c|}{1.27} \\
Thickness Correction Factor & 0.25 \\
\hline
\end{tabular}

\section{Fatigue Damage Summary}

DrcaFlex 10.0d: SCR4.ftg (modified 17:34 on 12/10/2018 by DrcaFlex 10.0d) Title:

Damage Calculation: Homogeneous pipe stress

Analysis Type: Rainflow

\begin{tabular}{|l|r|}
\hline \multicolumn{2}{|c|}{ Horst Damage } \\
\hline Damage over Total Exposure & $9.60 \mathrm{E}-01$ \\
Total Exposure Time (years) & 0.0006 \\
Life (years) & 102.25 \\
Arc Length (m) & 15.0 \\
Theta (deg) & 0.0 \\
SN-curve & S-N Curve1 \\
Radial Position & Outer \\
SCF & 1.27 \\
Thickness Correction Factor & 0.25 \\
\hline
\end{tabular}

Figure 7: Fatigue life report for the worst damage case for all the SCRs.

TABLE 4: Wave load cases

\begin{tabular}{lllll}
\hline \multicolumn{1}{c}{ Load Case No. } & Wave Direction & & $\begin{array}{c}\text { Height } \\
\text { Hs (ft) }\end{array}$ & $\begin{array}{c}\text { Period } \\
\mathrm{Tz}(\mathrm{ft})\end{array}$ \\
\cline { 3 - 5 } & & & 1.80 & 2.20 \\
Case01.dat & 0 & 1.85 & 4.50 \\
Case02.dat & 4 & 1.50 & 30.50 \\
Case03.dat & 135 & 4.90 & 18.50 \\
Case04.dat & 180 & 6.50 & 24.50 \\
Case05.dat & 245 & 8.20 & 30.50 \\
Case06.dat & 300 & 9.50 & 20.50 \\
Case07.dat & 180 & 2.55 & 35.00 \\
Case08.dat & 0 & & \\
\hline
\end{tabular}

\section{ACKNOWLEDGMENT}

This work was supported by the Nigerian Content Development and Monitoring Board (NCDMB) and TechnipFMC under a Research and Development scholarship scheme. However, the observations, results, conclusions, and recommendations expressed in this work are those of the authors. 


\section{NOMENCLATURE}

$\begin{array}{ll}C_{d} & \text {-Drag coefficient (-). } \\ C_{m} & \text {-Coefficient of inertia (-). } \\ \ddot{U} & \text {-Acceleration component of water particle. } \\ \dot{U} & \text {-Water particle velocity }(\mathrm{m} / \mathrm{s}) . \\ A & \text {-Cross-sectional area }\left(\mathrm{m}^{2}\right) . \\ D_{\mathrm{FOS}} & \text {-Design factor of safety for fatigue (-). } \\ F_{a} & \text {-Design Yield strength factor }(-) . \\ F_{D} & \text {-Design Tensile strength factor }(-) . \\ O D & \text {-Outer Diameter (m). } \\ P e & \text {-Pressure external (MPa). } \\ \mathrm{P}_{\mathrm{L} 1} & \text {-Local incidental pressure (MPa). } \\ S N & \text {-Stress to Number of Cycles to Failure } \\ \mathrm{t}_{\text {cor }} & \text {-Corrosion allowance on WT (m). } \\ \mathrm{t}_{\text {norm }} & \text {-Uncorroded pipe Wall Thickness, } \\ & \text { Nominal (m). } \\ V & \left.\text {-Volume of the structure (m }{ }^{3}\right) \\ \gamma_{a} & \text {-Resistance Factor due to properties of } \\ & \text { materials uncertainties. } \\ \gamma_{\mathrm{SC}} & \text {-Resistance Factor relative to Safety Class. }\end{array}$

\section{REFERENCES}

Ruswandi, M. I. (2009). Improvisation of Deep Water Weight Distributed Steel Catenary Riser. Norway: University of Stavanger.

Campbell, M. (1999). The Complexities of Fatigue Analysis for Deepwater Risers. Proceedings of the Deepwater Pipeline Technology Conference. New Orleans, pp.32-40.

Buberg, T. (2014). Design and Analysis of Steel Catenary Riser Systems for Deep Waters. Master's Thesis, Norwegian University of Science and Technology,Norway,pp.98-104.

DNV-RP-F204;. (2010). Riser Fatigue. Det Norske Veritas,Norway, pp. 20-56.

Karunakaran, D., Kristoffersen, S., \& Subsea 7. (2005). Weight Optimized SCRs for Deepwater Harsh Environments. Offshore Technology Conference, 2-5 May. Houston, Texas.

Bridge, I., \& Howells, H. (2007). Observations and Modelling of Steel Catenary Risers Trenches. 17th International Offshore and Polar Engineering Conference. Lisbon, Portugal,pp.803-813.

Nelson, A. L., Folley, K. W., \& Coral, M. (1952). Differential Equations. Boston: D.C. Heath and Co.

Song, R. S. (2009). Advances in deep water steel catenary riser technology state of the art. ASME 28th International Conference on ocean, (pp. 285-290). Honolulu: Offshore and Arctic Engineering.

DNV-OS-F201. (2010). Dynamic Riser. Det Norske Veritas,Norway, pp 16-40.

DNVGL-RP. (2014). Fatigue design of offshore steel structures. Det Norske Veritas, Norway, pp. 21-30.

Chandrasekaran, S. (2018). Dynamic Analysis and Design of Offshore Structures. New Delhi, India: Springe,pp 50-56.

Ochi, M. K., \& Hubble, E. N. (1976). Six Parameter wave spectra. 15th Coastal Engineering Conference, (pp. 301-328).

Orcina;. (2011). OrcaFlex User Manual 9.5a. UK: Orcina, www.orcina. 